\title{
An experimental study of burnout and flow instability in sub-channels with subcooled void at low pressure
}

\author{
V. Chatoorgoon \\ Dept. of Mechanical Engineering, University of Manitoba, Canada
}

\begin{abstract}
An experimental study was undertaken to rationalize data obtained from previous experiments where the bundle was heated electrically until CHF occurred, destroying ultimately the test bundle. (We term this 'burnout' from here on). The bundle exit temperature was always subcooled; hence, the channels contained only subcooled void preceding 'burnout'. This study was undertaken to perform controlled experiments leading up to, but not including, the burnout power. Just prior to 'burnout' microscopic flow oscillations were exhibited between sub-channels. This was an interesting finding, as while the burnout power (especially for these bundles under sub-cooled boiling conditions) cannot be determined consistently with good accuracy through analytical methods, numerical methods for predicting the onset of flow oscillations are more accurate and well established. A stability analysis of the sub-channels of the single bundle, albeit without communication between the channels, was performed. Surprisingly, the predicted power at the onset of flow oscillations followed closely the experimental burnout power (of course, the latter was always slightly greater than the former, as would be expected).
\end{abstract}

Keywords: CHF, flow instability, subcooled boiling, fuel bundle, low pressure.

\section{Introduction}

Two-phase flow instabilities have been well researched, both experimentally and analytically. The analytical methods used for predicting them are also well established and have been abundantly benchmarked. However, in most reported experimental or analytical studies, the system considered was in a state of bulk boiling preceded by some small region of sub-cooled boiling. In all reported 
cases the sub-cooled boiling region had no more than a minor impact on the overall system stability.

It is rare when the entire system considered is subcooled and the instabilities are caused by subcooled void only. It is also rare when the system pressure is low and near atmospheric. Hainoun and Schaffrath [1] reported a numerical study of flow instabilities due to subcooled boiling. Their paper investigated primarily the steady-state pressure-drop versus flow-rate characteristic due to subcooled boiling. No results of actual flow oscillations, or instabilities, are presented. The cited reference does allude to subcooled boiling instability experiments done at Oak Ridge, but those results were not reported. The system pressure was $1.7 \mathrm{MPa}$. Stoddard et al. [2] studied experimentally and analytically the onset of flow instability and critical heat flux in micro-channels with subcooled void at $\sim 1 \mathrm{MPa}$ and found that the onset of flow instability just preceded CHF. They also reported poor agreement between the measured CHF values and predicted values from recommended correlations.

Other than those referenced works, no experimental data on the instability of low-pressure, two-phase systems driven solely by sub-cooled boiling could be found. The information presented herein could be used to verify void models and/or validate thermal hydraulic codes. Three low-pressure, subcooled void driven instability experiments are presented.

The candidate bundle used in this study is labelled bundle ' $M$ ' for ease of communication. In previous tests the ' $\mathrm{M}$ ' assembly was subjected to increasing powers at a constant forced inlet flow rate until burnout occurred. In those tests burnout invariably occurred before bulk boiling was attained at the bundle exit -indicating that the exit flow temperature was less than the saturation temperature. The primary objective of those experiments was to determine the burnout power and not necessarily to understand the flow dynamics leading up to burnout.

Even though this generic study was conducted at low pressure and with simulated fuel bundles, the information gathered could provide useful insight into flow dynamics just before burnout occurs in fuel bundles.

\section{Objectives}

The objectives of these experiments were to:

(a) Gather data on parallel channel flow instability in a set of electricallyheated assemblies that would be useful for code validation

(b) Determine the power at the onset of flow instability (OFI)

(c) Determine whether the power at OFI, in a parallel arrangement with other similar assemblies, is related in any way to the burnout power obtained in single-assembly tests.

Unlike the burnout tests mentioned above, the ' $M$ ' assembly in these experiments was situated in parallel with two other assemblies (labelled the ' $\mathrm{H}$ ' and ' $\mathrm{C}$ ' assemblies). The total flow rate through all three assemblies was constant. 


\section{Test facility}

The test loop used is shown in Fig. 1. It consisted of three parallel assemblies mounted on a common plenum (shown in Fig. 2) that was situated at the bottom of a large tank. Deionized light water was pumped from a holding reservoir into the plenum using a centrifugal pump. The coolant was driven upward through the heater assemblies after which it was returned to a holding reservoir located adjacent to the $40 \mathrm{hp}$ pump. The flow exiting the heater assemblies was passed through a heat exchanger situated upstream of the holding reservoir to remove the added heat. The outlet of each heater assembly was connected to a common header, which in turn was connected to the heat exchanger inlet piping.

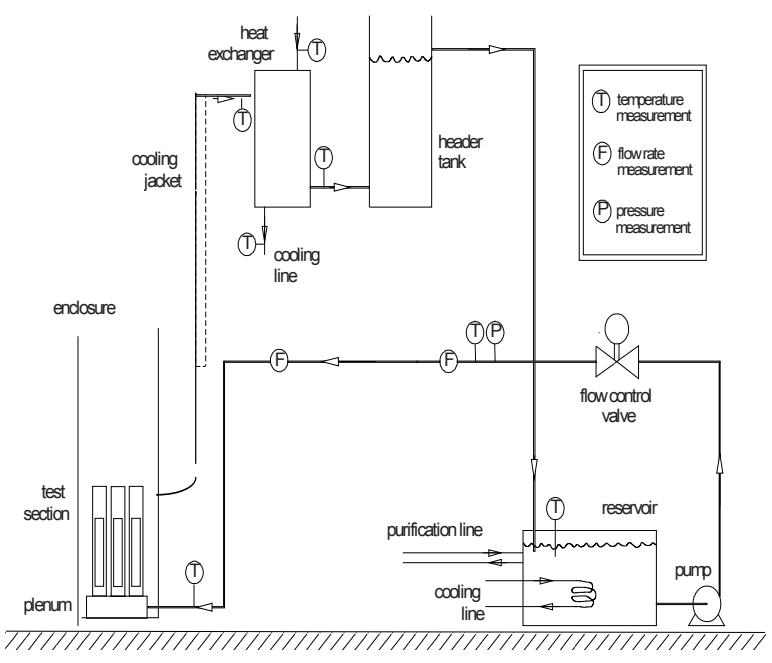

Figure 1: Schematic of flow loop.

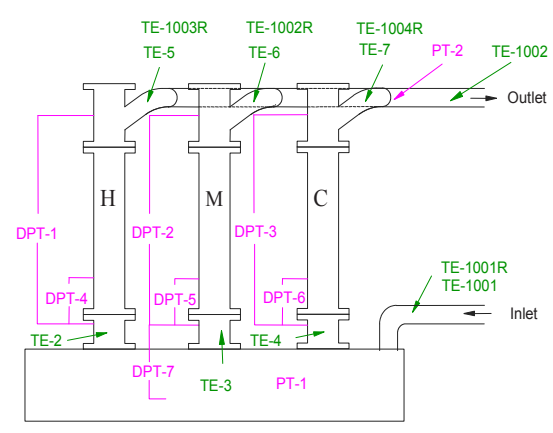

Figure 2: Details of instrumentation. 


\section{Heater assemblies}

Three different types of assemblies were used -- an $\mathrm{H}$ assembly, which comprised 7 finned elements; a C assembly, which comprised 6 finned elements, and the $\mathrm{M}$ assembly, which comprised 4 smooth elements. The tube around each heater assembly was made of a polycarbonate material and was fabricated specially for these assemblies. Each assembly was mounted on a spool piece, which was then mounted directly onto the plenum. All three assemblies were heated electrically using a DC power source with a total capacity of $1.7 \mathrm{MW}$.

The $\mathrm{H}$ assembly comprised 7 heater elements, each of length $0.6 \mathrm{~m}$. It had a cosine-shaped axial heat-flux profile. The $\mathrm{C}$ assembly comprised 6 heater elements of length $0.6 \mathrm{~m}$. It also had a cosine-shaped axial heat-flux profile. The $\mathrm{M}$ assembly comprised 4 heater elements of length $0.47 \mathrm{~m}$. It had a uniform axial heat-flux profile.

\section{Power connections}

All three assemblies were connected electrically in a simple parallel arrangement. This delivered about $56 \%$ of the total power to the $\mathrm{M}$ assembly, $25 \%$ to the $\mathrm{H}$ assembly and $19 \%$ to the $\mathrm{C}$ assembly. This arrangement was chosen so as to introduce subcooled boiling in the $\mathrm{M}$ assembly while maintaining single-phase flow in the $\mathrm{H}$ and $\mathrm{C}$ assemblies. The $\mathrm{H}$ and $\mathrm{C}$ assemblies comprised indirect heaters whereas the $\mathrm{M}$ assembly was heated directly. The power distribution between the assemblies varied slightly with the applied power.

\section{Instrumentation}

The test facility was instrumented to measure coolant temperature, pressure, pressure-drop and assembly power. The flow rates through the $\mathrm{H}$ and $\mathrm{C}$ assemblies were deduced from DP cell pressure-drop measurements across the inlet of each assembly. These inlet DP cells were previously calibrated against known flow rates. An independent verification of the flow rate was also obtained from an energy balance applied across the assembly.

\subsection{Steady-state flow rate}

Steady-state flow rates in the three assemblies were determined as follows:

- Total loop flow rates were obtained from the FT-2 and FT-5 flow meters.

- $\quad$ Flow rates into the $\mathrm{H}$ and $\mathrm{C}$ assemblies were deduced from pressuredrop measurements obtained across the inlet end plates and also from an energy balance across each assembly.

- $\quad$ Flow rate through the $\mathrm{M}$ assembly was deduced from an energy balance across that assembly and also from subtracting the $\mathrm{H}$ and $\mathrm{C}$ assemblies flow rates from the total flow rate. 


\subsection{Pressure and pressure-drop}

The following pressure and pressure-drop measurements were made:

- $\quad$ absolute pressure in the plenum; made with a Rosemount pressure cell.

- differential pressure across each inlet end-plate of the $\mathrm{H}$ and $\mathrm{C}$ assemblies; obtained with Sensotec DP cells.

- differential pressure across the inlet spool piece of the M assembly; obtained with a Sensotec DP cell.

- differential pressure across each assembly, made with a Rosemount DP cell.

\subsection{Transient/oscillatory flow rate and pressure-drop}

Transient or oscillatory flow rate was not measured directly because of the inherent difficulties in accurately measuring an oscillating flow rate. However, the transient/oscillatory pressure-drop across the $\mathrm{H}$ and $\mathrm{C}$ inlet end plates (DPT-4 and DPT-6), and the M inlet spool piece (DPT-5), were measured using fastresponse Sensotec DP cells. These fast-acting Sensotec DP cells were sufficiently sensitive to capture details of the dynamics. The Sensotec DP cell placed across the inlet spool piece of the $\mathrm{M}$ assembly for recording oscillations in the inlet pressure-drop caused by oscillations in the inlet flow rate would not necessarily measure pressure oscillations between sub-channels of the $\mathrm{M}$ assembly. However, they were found to provide an indication of such oscillations. Oscillations in pressure-drop at any given location would indicate oscillations in the flow rate at that location. The frequency and phasing of the pressure-drop oscillations could be translated into a corresponding frequency and phasing of flow rate oscillations. The measured pressure-drop values could be compared directly with numerical predictions of pressure drop response. If they matched well, the corresponding calculated flow rates would be deemed realistic.

\subsection{Temperature}

The following temperatures were measured:

* inlet temperature to the plenum.

* inlet and outlet temperature of each bundle using thermocouples and RTDs.

* outlet temperature of all four inner channels of the M assembly using thermocouples.

* temperature in the outlet header using a thermocouple and RTD.

\subsection{Assembly power}

The assembly power was determined by measuring the current through each assembly and the voltage drop across each assembly. From the known resistance of the assembly and the measured voltage drop, a direct value of the applied power to each assembly was derived. An indirect value applied power was also deduced from an energy balance. The measured pressure-drop across each inlet 
end plate yielded a corresponding flow rate from the calibration curves. Combining this with the measured inlet and outlet temperatures from each assembly, the assembly power was calculated from the standard formula,

$$
\text { Power }=\dot{m} C_{p}\left(T_{\text {out }}-T_{\text {in }}\right)
$$

where $\dot{m}$ is the mass flow rate, $C_{p}$ is the specific heat and $\left(T_{\text {out }}-T_{\text {in }}\right)$ is the difference between the outlet and inlet temperatures. Of course, Eq. (1) is only strictly valid for single-phase flow. When two-phase flow occurs at the outlet, an error is introduced that is dependent on the energy content of the vapour.

\section{Measurement uncertainty and errors}

Precautions were taken to reduce experimental uncertainty and measurement errors. Due to brevity of space, this information is available, but omitted here.

\section{Data acquisition system}

A PC-based Data Acquisition System (DAS) and a Noise Analysis System (NAS) were used to collect, process and store the measured data. The DAS was used for recording steady or quasi-steady data while the NAS was used for recording unsteady, transient data. The NAS was developed for collecting data up to frequencies of $1 \mathrm{kHz}$. The pressure-drop versus flow-rate characteristic of the inlet end plates of the $\mathrm{H}$ and $\mathrm{C}$ assemblies and the inlet spool piece of the $\mathrm{M}$ assembly were programmed into the DAS. Thus, direct values of flow rate were obtained from the DP cells connected across the $\mathrm{H}$ and $\mathrm{C}$ inlet end plates and the $\mathrm{M}$ inlet spool piece. Conversion of the raw data into the required engineering units was also performed automatically by the DAS. Further processing of the results into useful graphical displays was done using spreadsheet software.

\section{Experimental procedure}

\subsection{Stability tests}

The purpose of these tests was to examine the stability characteristics of the M assembly with sub-cooled void while the $\mathrm{H}$ and $\mathrm{C}$ assemblies were with singlephase conditions throughout. Specifically, the intent was to determine the $\mathrm{M}$ assembly power at the onset of flow instability (OFI). For this reason, the $\mathrm{H}$ and $\mathrm{C}$ assemblies were heated with only $25 \%$ and $19 \%$ respectively of the total applied power while the $\mathrm{M}$ assembly received the remaining $56 \%$.

Three stability tests were done, all with a constant plenum temperature of $30^{\circ} \mathrm{C}$. Commencing at zero power and a pre-set inlet flow velocity to the $\mathrm{M}$ assembly, the total power applied to all three assemblies was increased in increments of about $25 \mathrm{~kW}$ until significant void (determined visually) was noticed in the outer channels of the $\mathrm{M}$ assembly. All the system parameters (temperature, pressure, pressure-drop, flow rate, current and voltage) were 
continually recorded by the DAS from the start of each test. The NAS data collection was activated and synchronized with the DAS when the total applied power reached $100 \mathrm{~kW}$. The scan rate on the DAS was every 2 seconds. The scan rate on the NAS was every 0.01 -second for the duration of the experiment.

The onset of nucleate boiling (ONB) was deduced (approximately) by listening for the change in sound emanating from the assemblies. (The onset of nucleate boiling on the inner channels of the $M$ assembly could not be ascertained by this procedure as the sound from those channels was inaudible.) After each power increment the system was allowed time to settle down to a new steady state. This was determined by observing the $M$ assembly outlet temperature on the DAS and waiting for it to become constant. After OSV was deduced to be attained in the $\mathrm{M}$ assembly, the total power increments were reduced to $\sim 10 \mathrm{~kW}$ until the $\mathrm{M}$ inlet spool-piece pressure drop, monitored continually on an oscilloscope, showed small-scale oscillations. Thereafter the total power increments were reduced to about $5 \mathrm{~kW}$, or less, until flow oscillations or instability was clearly evident on the oscilloscope.

The onset of flow oscillations (OFO) is distinctly different from the onset of flow instability (OFI). The former precedes the latter slightly. The OFI point is defined as that point where the oscillation amplitudes begin to diverge. Once the OFI power was determined, further increases in the total power were discontinued to protect the assemblies. After allowing sufficient time for data collection, the total power was reduced in preparation for the next test. The inlet velocity to the $M$ was reset to a different value and the experimental process repeated. Three tests were done corresponding to average inlet velocities in the $\mathrm{M}$ assembly of 3.36, 2.43 and $1.09 \mathrm{~m} / \mathrm{s}$. The average velocity was determined by dividing the net flow rate through the $\mathrm{M}$ assembly by the product of the net flow area and the inlet flow density. For inlet velocities of 2.43 and $1.09 \mathrm{~m} / \mathrm{s}$, the repeatability of the experiments was assessed and confirmed. After flow instability was identified in the first power sweep, the total power was reduced briefly and increased again until OFI reoccurred. It was found that diverging flow oscillations appeared exactly at the same power (i.e. within $1-2 \mathrm{~kW}$ ) as was obtained in the first sweep. This confirmed that the experiments were repeatable and the results were reproducible. During the tests, the test-section was also continuously filmed using two video cameras. The flow oscillations were, therefore, captured on film.

\section{Experimental results}

A summary of the test conditions at OFI in the M assembly, for the three tests performed, are given in Table 1. The onset of flow instability (OFI) is defined as that point where the oscillation amplitudes began to diverge with time, as inferred from the inlet pressure-drop oscillations. These oscillations may not have been noticeable with the naked eye, but they were measurable. The onset of flow instability for the M-assembly inlet spool piece for the three tests is shown in Figs. 3-6. Also shown is the inlet end-plate pressure drop for the $\mathrm{H}$ and $\mathrm{C}$ assemblies. 
A cautionary note on comparing the magnitudes of the pressure-drop oscillations of the $\mathrm{M}$-assembly inlet spool piece with the $\mathrm{H}$ and $\mathrm{C}$ assemblies' inlet end plate; the M-assembly inlet spool piece inherently had a low-pressure drop due to its open area. Thus, small-scale oscillations do not necessarily mean low amplitude flow oscillations. Flow oscillations between the inner and outer channels of the $\mathrm{M}$ assembly would induce oscillations in the inlet spool piece when the conditions and channel geometry are unequal. Since the inner and outer channels of the $\mathrm{M}$ were different, with different powers and flow conditions, any oscillations between the inner and outer channels would also induce oscillations in the flow within the inlet spool piece. Hence, the pressure oscillations across the M inlet spool piece recorded by the Sensotec DP cell are a result of the inner channel dynamics as well as the coupled dynamics between the $\mathrm{M}$ assembly and the $\mathrm{H}$ and $\mathrm{C}$ assemblies.

Figs. 3-5 show that the inlet flow to the $\mathrm{H}$ and $\mathrm{C}$ assemblies always oscillated in phase - an expected result since both assemblies were always with singlephase flow. Therefore, the $\mathrm{H}$ and $\mathrm{C}$ assemblies behaved, as expected, as a single assembly. With the apparent exception of the 3CH5 test, which is discussed subsequently, Figs. 3 and 4 show that, for the $3 \mathrm{CH} 3$ and $3 \mathrm{CH} 4$ tests, the $\mathrm{M}$ inlet spool piece pressure drop is almost, but not exactly, 180 degrees out of phase with the $\mathrm{H}$ and $\mathrm{C}$ assemblies' inlet end-plate pressure drop. However, the

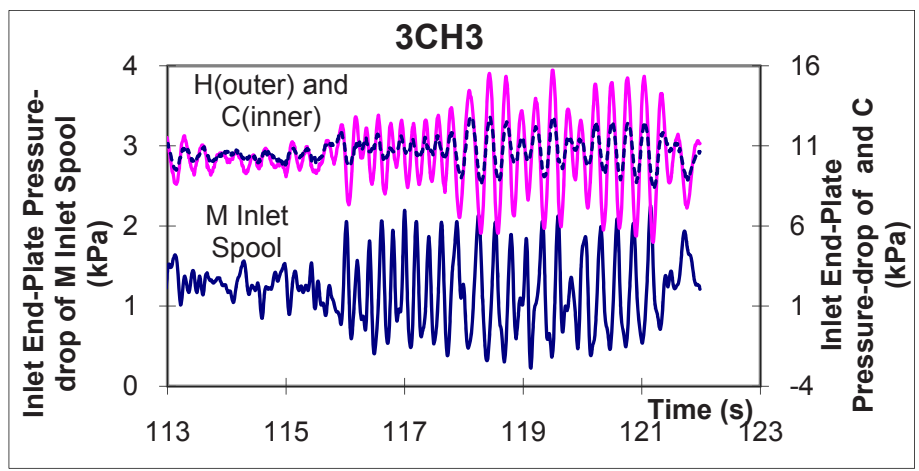

Figure 3: Onset of flow instability for test $3 \mathrm{CH} 3$.

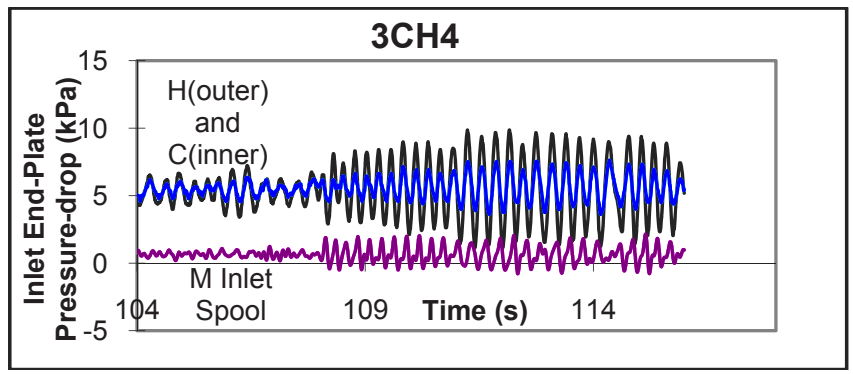

Figure 4: Onset of flow instability for test 3CH4. 


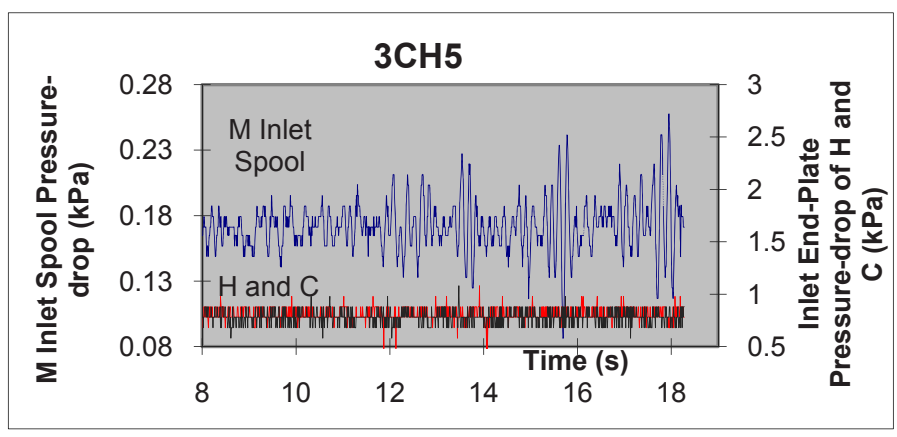

Figure 5: $\quad$ Onset of flow instability for test 3CH5 (130.7 kW).

periods of oscillation are equal. This indicates that the $\mathrm{M}$ assembly, for the $3 \mathrm{CH} 3$ and $3 \mathrm{CH} 4$ tests, behaved almost like a 'single' entity. Because the phase difference was slightly less than $180^{\circ}$, this indicates the possibility of some dynamic motions within the $\mathrm{M}$ assembly itself. If the $\mathrm{M}$ assembly behaved perfectly like a single entity, then its response would have been exactly $180^{\circ}$ out of phase with the $\mathrm{H}$ and $\mathrm{C}$ assemblies' inlet pressure-drop oscillations. It was already established that the $\mathrm{H}$ and $\mathrm{C}$ assemblies behaved like a single entity. The lowest velocity test $(3 \mathrm{CH} 5)$ shows a different behaviour from the $3 \mathrm{CH} 3$ and 3CH4 tests (Fig. 5). Like before, Fig. 5 shows that the $\mathrm{H}$ and $\mathrm{C}$ assemblies' inlet pressure oscillations were always in phase with each other. However, the period of oscillation of the $\mathrm{H}$ and $\mathrm{C}$ assemblies has now doubled ( $\sim 0.40$ second) to about twice the period of oscillation of the $\mathrm{M}$ assembly. A plausible explanation is not obvious, but this result indicates that some dynamic motions may be occurring within the $\mathrm{M}$ assembly, especially at this lower flow rate.

The inlet flow oscillations in the M-assembly inlet spool piece (Fig. 5) at OFI clearly show two oscillation frequencies -- one with a period of about 0.2 second and the other with a period of about 2.0 seconds. There is no noticeable flow oscillation in the $\mathrm{H}$ and $\mathrm{C}$ assemblies in Fig. 5. It is possible that they were too small to be picked up at this power (130.7 kW in the M assembly).

Because the $\mathrm{H}$ and $\mathrm{C}$ assemblies always acted in phase and exhibited the same period, while the period of the oscillation in the $M$ inlet spool piece was half the period of the oscillations in the $\mathrm{H}$ and $\mathrm{C}$ assemblies, this observation indicates that the $\mathrm{M}$ assembly behaved like multiple channels with phase differences. No other explanation is evident. Figs. 3-5 show evidence of two oscillation periods in the $\mathrm{M}$ assembly -- one of about 0.2 second and the other of about 2.0 seconds. However, the dominant mode seems to be the 0.2 -second period. The period of oscillation in the $\mathrm{H}$ and $\mathrm{C}$ assemblies is about 0.4 seconds.

A plot of the M-assembly power at OFI versus average inlet velocity is shown in Fig. 6. Also shown is the burnout power obtained in previous burnout tests. It is noteworthy that the three OFI data points fall very close to the burnout data, suggesting a connection between burnout power and OFI power. It seems very plausible that in the single M-assembly burnout tests flow oscillations, and/or 
flow instability, were a precursor to burnout. Fig. 6 presents the OFI data in the non-dimensional form of $\frac{N_{p}}{N_{s}}$ versus $N_{s}$ where $N_{p}$ and $N_{s}$ are the wellknown Zuber and subcooling numbers respectively. The OFI data is approximated well by $\frac{N_{p}}{N_{s}} \approx 0.46$.

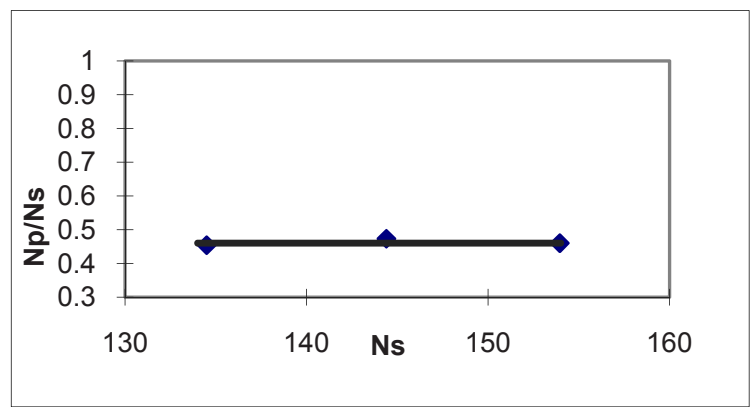

Figure 6: $\mathrm{Np} / \mathrm{Ns}$ versus Ns for the M assembly.

A plot of the M-assembly power at OFI versus average inlet velocity is shown in Fig. 7. Also shown is the burnout power obtained in previous burnout tests. It is interesting that the three OFI data points fall very close to the burnout data, suggesting a connection between burnout power and OFI power. It seems very plausible that in the single M-assembly burnout tests flow oscillations, and/or flow instability, were a precursor to burnout.

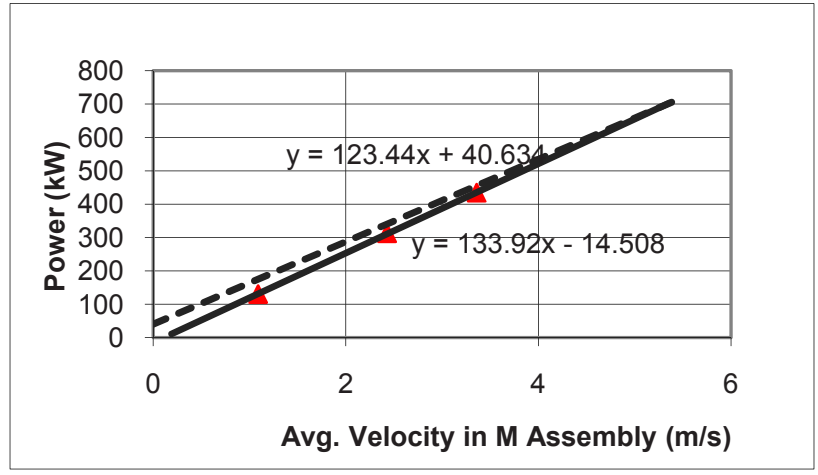

Figure 7: $\quad$ OFI power versus average inlet velocity for the M assembly.

Fig. 8 shows the comparison between burnout data and numerical prediction of incipient flow oscillations in the sub-M-assembly channels. The trend is similar, with the instability predictions slightly under the burnout data. 


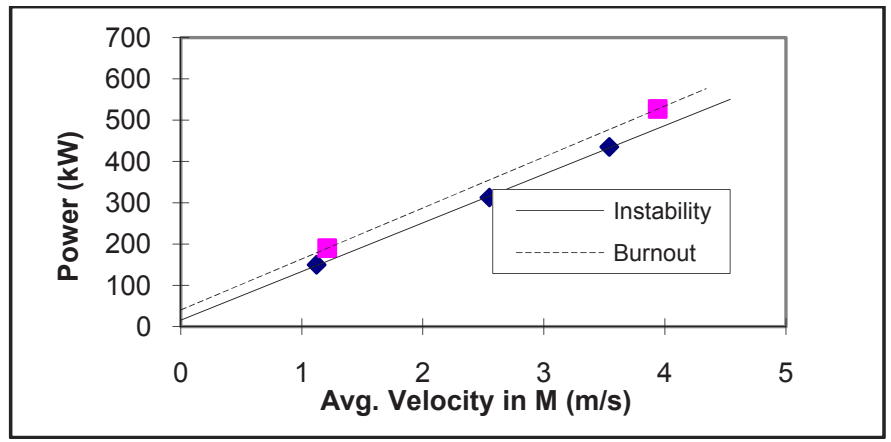

Figure 8: Comparison between burnout data in the $\mathrm{M}$ assembly vs. prediction of incipient flow oscillations using an instability numerical program (SPORTS).

\section{Conclusions}

\section{M-assembly Stability Tests}

The following were the findings of this study:

(a) Nucleate boiling precipitated flow oscillations. (b) Oscillations occurred between sub-channels of the $\mathrm{M}$ assembly, as well as between the $\mathrm{M}$ assembly and other assemblies.

(c) The onset of flow oscillations and instability (OFI) just preceded the singleassembly burnout, indicating a possible connection between burnout and OFI.

(d) If (c) is true, conditions just before burnout may be predictable through a numerical stability analysis of the assembly sub-channels.

(e) OFI occurred at an $\frac{N_{p}}{N_{s}} \approx 0.46$. This may be useful for scaling the data for pressure, velocity and sub-cooling effects.

(f) The close proximity of the OFI data to the single-assembly burnout data suggests that the burnout power is not significantly affected by the presence of other parallel assemblies.

It is unknown at this time whether points (b) and (c) would apply to CHF in fuel bundles, and whether flow oscillations between channels would occur and influence CHF. Further studies need to be undertaken to confirm whether this finding is generally applicable, or whether it is just a unique characteristic of this bundle geometry.

\section{Acknowledgements}

Sincere thanks are expressed to Dr. N. Popov for supporting this generic study and to Dr. H. Rummens for her invaluable technical expertise in designing the experiment. The experimental work was performed while at the Chalk River Laboratories of Atomic Energy of Canada, Ltd. (AECL-CRL). The experimental 
data presented in this paper are shared with permission from AECL-CRL. The interpretations of the data are those of the author.

\section{References}

[1] Hainoun, A., Schaffrath, A., 2001. Simulation of sub-cooled flow instability for high flux research reactors using the ATHLET code, Nucl. Eng. \& Design, 207, p. 163-180.

[2] Stoddard, R.M., Blasick, A.M., et al., 2002. Onset of flow instability and critical heat flux in thin horizontal annuli, Experimental Thermal and Fluid Science, Vol. 26, Issue 1, April, p. 1-14. 